\title{
The Thrombogram: Monitoring Thrombin Generation in Platelet Rich Plasma
}

\author{
H. Coenraad Hemker, Peter L A. Giesen, Manoj Ramjee ${ }^{1}$, Rob Wagenvoord, \\ Suzette Béguin
}

From the Department of Biochemistry and Synapse BV, Cardiova scular Research Institute (CARIM) Maastric ht, The Netherlands; ${ }^{1}$ Peptide Thera peutics Ltd., Cambridge, United Kingdom

\section{Key words}

Thrombin generation, thrombin potential, thrombogram, platelet rich plasma

\section{Summary}

A method is described in which thrombin activity in clotting plasma can be monitored through the continuous measurement of the fluorescent split-product of the substrate Z-Gly-Gly-Arg-AMC. The signal is not impaired by turbidity; therefore proper measurement is not disturbed by the occurrence of a clot or the presence of platelets and direct measurement in platelet rich plasma is possible.

\section{Introduction}

The thrombin activity that generates at the site of a lesion is an important determinant of the extent of the haemostatic-thrombotic reaction that ensues. Most of the thrombin $(>95 \%)$ generates after the moment of clotting, therefore the clotting time is not automatically a good indicator of thrombin activity. Thrombin activity in clotting blood is a transient phenomenon and therefore should be measured during the clotting process. It can be quantified by measuring the amount of product that is produced from an artificial thrombin substrate during coagulation. This amount is proportional to the area under the thrombin generation curve, i.e. the endogenous thrombin potential (ETP) (1).

The thrombin generation curve, or thrombogram, reflects the action of the total clotting mechanism. In vitro the mechanism engaged is dependent upon the trigger used. Probably the clotting of whole blood in the presence of a small amount of tissue factor comes closest to the physiological situation.

The thrombogram is classically obtained via determination of the thrombin content in small subsamples taken at short intervals from clotting blood or plasma $(2,3)$. This method is so labor intensive as to preclude its application in clinical or pharmaceutical routine. Previously we have described a method to obtain the thrombogram automatically via the color production from specially designed "slow" thrombin substrates (1). This requires optically clear media so that it can be only applied to defibrinated plasma. Platelet rich plasma (PRP) and whole blood still require subsampling. Because thrombin generation in PRP appears to reveal important interactions between the platelets and the clotting system, including fibrin (4), we have developed a method to monitor thrombin generation automatically in PRP.

Correspondence to: Prof. H. C. Hemker, Synapse B.V. Universiteit Maastricht, P.O. Box 6166200 MD Maastricht, The Netherlands - Tel.: +3143388 1675; Fax: +3143367 09 88; E-mail: Coen.Hemker@thrombin.com

\section{Materials and Methods}

Reagents

The fluorogenic substrate Z-GGR-AMC (Bachem, Switzerland) was solved to a concentration of $5 \mathrm{mM}$ in buffer containing 10\% DMSO. The solution should be freshly prepared or stored at $-20^{\circ} \mathrm{C}$. As a buffer we used $20 \mathrm{mM}$ HEPES, $150 \mathrm{mM} \mathrm{NaCl}$, with $60 \mathrm{mg} / \mathrm{ml}$ bovine serum albumin (BSA; Lot A-7030, Sigma), pH 7.35. Recombinant tissue factor (rTF) was a kind gift of Prof. Yale Nemerson (New York). All other chemicals were reagent grade, commercially available.

\section{Preparation of Plasma}

PRP was obtained by centrifuging freshly drawn citrated blood ( 9 parts of blood to one part of $0.13 \mathrm{M}$ trisodium citrate) at $250 \mathrm{~g}, 15^{\circ} \mathrm{C}$ for $10 \mathrm{~min}$. The platelet count was adjusted to $3 \times 10^{8} / \mathrm{ml}$ using autologous PPP, made by double centrifugation of PRP at $1000 \mathrm{~g}, 15^{\circ} \mathrm{C}$ for $10 \mathrm{~min}$. Heat inactivated plasma was PPP incubated for $30 \mathrm{~min}$. at $56^{\circ} \mathrm{C}$. It was checked that no clotting factors or antithrombin activity persisted.

\section{Measurement of Thrombin Generation}

Per well of a 96-well microtiter plate we added $80 \mu \mathrm{l}$ of PRP and $20 \mu \mathrm{l}$ of buffer that may contain a drug, an antibody or another substance to be tested and $1 \mathrm{pM}$ of rTF. The reaction is started by adding $20 \mu \mathrm{l}$ of the substrate solution containing $0.1 \mathrm{M} \mathrm{CaCl}_{2}$. The final concentrations therefore were: Plasma (citrated): 2:3 diluted; platelets, if present: 200,000 per $\mu$ l; substrate: $833 \mu \mathrm{M}$; DMSO: 1,67\%; rTF: 0.17 pM; $\mathrm{CaCl}_{2}: 16.7 \mathrm{mM}$.

The microtiter plate fluorometer used is the Fluoroskan Ascent, type 374 (Labsystems, Helsinki, Finland) with an excitation filter at $390 \mathrm{nM}$ and an emission filter at $460 \mathrm{nM}$. Fluorescence was measured from the bottom in 96well clear-bottom plates. Fluorescence was measured in each well at $30 \mathrm{~s}$ intervals during $30 \mathrm{~min}$. Typically six identical experiments were run in parallel allowing 16 experiments to be carried out simultaneously.

Thrombin amidolytic activities were calculated by comparing the arbitrary fluorescence values, corrected for the inner filter effect, to those of a standard calibration curve, prepared with known amounts of active-site titrated human $\alpha$-thrombin in heated plasma. A linear increase of the fluorescent signal is seen as long as it remains $<1000$ arbitrary units, as in our experiments.

In control experiments, thrombin generation was determined with the subsampling method as reported in detail elsewhere $(5,6)$.

\section{Data Management}

The course of the fluorescent signal from each of the wells is retrieved in an Excel spreadsheet (1). The mean of 6 parallel experiments is obtained as follows: 1: Determination of the lag-time of thrombin formation. We define the lag time as the moment that the fluorescent signal deviates from a horizontal line by more than $2 \times \mathrm{SD}$. The lag-time is measured for each of the curves and the mean $( \pm \mathrm{SD})$ is calculated. 2: The curves are shifted along the time axis, in order to equalize their lag-times. The mean lag-time is calculated. 3: At each 
time point the mean value $( \pm$ SD) of the fluorescent signal is calculated. The time course and confidence limits of thrombin activity is obtained as the first derivative of the mean curve ( $\pm \mathrm{SD})$. 4 . Correction for the residual $\alpha 2$-macroglobulin-thrombin activity was carried out according to the algorithm published earlier (7). (The algorithm can be found on website www.thrombin.com). 5) The first derivative of the fluorescence-time curve reflects the course of thrombin activity in the sample, analogous to the procedure in which a chromogenic substrate is used (1). Software is being developed to perform operations 1 through 5 in (near to) real time during the experiment.

\section{Results}

Any substrate protects thrombin from antithrombin action by keeping part of the thrombin bound in an enzyme-substrate complex. The fluorogenic substrate, when added in the subsampling method to a final concentration of $0.833 \mathrm{mM}$, increases the area under the thrombin

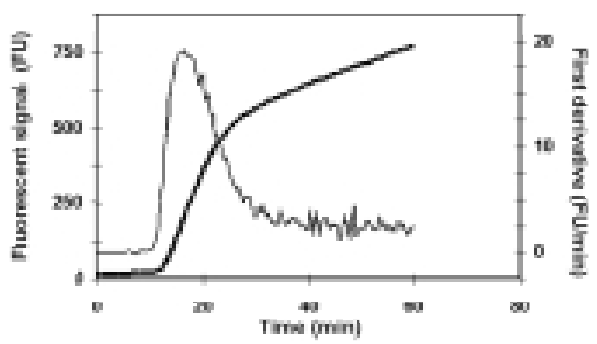

Fig. 1 Continuous determination of thrombin generation in platelet rich plasma. Thick line: fluorescent signal; thin line: first derivative. Data from one single experiment

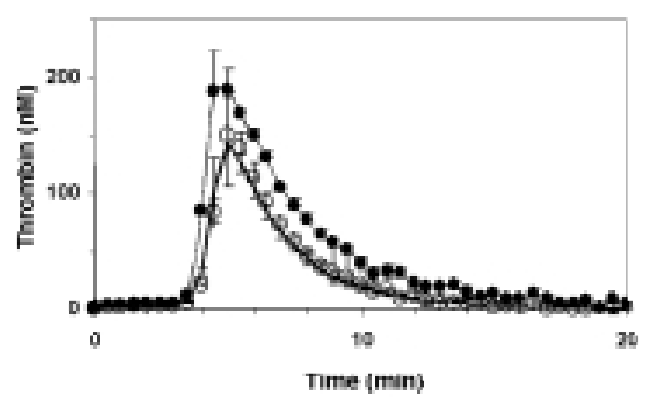

Fig. 2 The thrombogram in platelet poor plasma. Drawn line (no points): pooled normal plasma; $\bigcirc$ : patient before heparin administration; $\bigcirc$ (points only): patient after heparin. Means of six simultaneous experiments. (In order not to overload the figure, the points were omitted in the graph from pooled normal plasma and the line in the graph from patient plasma after medication)

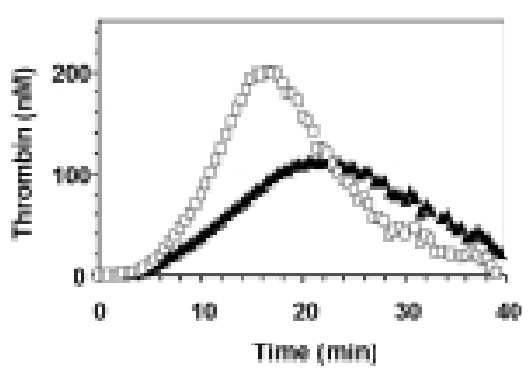

Fig. 3 The thrombogram in platelet rich plasma. $\square$ : normal donor; $\boldsymbol{\Delta}$ von Willebrand type 2a patient. Means of six simultaneous experiments generation curve of normal plasma to $735 \pm 99 \mathrm{nM} / \mathrm{min}$, as compared to a blank of $385 \pm 52 \mathrm{nM} / \mathrm{min}$. The influence of the DMSO, in the $1.67 \%$ final concentration required, on thrombin generation in PRP was also measured with the subsampling method. DMSO caused a slight $(<10 \%)$ prolongation of the lag phase and did not alter the shape and magnitude of the thrombin generation curve.

Fig. 1 shows the fluorescent signal as it is obtained from a single well in the fluorometer and the first derivative of that signal.

Fig. 2 shows thrombograms from normal, non-defibrinated pooled PPP, compared to the PPP from a patient with an increased activity of the clotting system, before and $2 \mathrm{~h}$ after administration of $5000 \mathrm{IU}$ of low molecular weight heparin (nadroparin) subcutaneously. The area under the curve obtained with pooled normal PPP is first expressed in arbitrary units (AU) of fluorescence intensity. In a parallel experiment we determined this area with the subsampling method and found it to be $374.6 \mathrm{nM} / \mathrm{min}$. From this the conversion factor between fluorescence units and $\mathrm{nM} / \mathrm{min}$ thrombin can be calculated (under our conditions $1 \mathrm{AU} / \mathrm{min}$ equals $0.192 \mathrm{nM}$ of thrombin). The ETP in the untreated patient was $595.4 \mathrm{nM} / \mathrm{min}$ (159\% of normal), after heparin administration it became $379 \mathrm{nM} / \mathrm{min}$ (101\% of normal).

Fig. 3 shows a curve in PRP from a normal control and a mild von Willebrand patient (type 2a, 35\% antigen activity, $\sim 5 \%$ ristocetin cofactor activity). The abnormality of the thrombogram in the patient is obvious from the shape of the curve; the area under the curve (ETP) is decreased by $14 \%$.

\section{Discussion}

The role of thrombin generation in haemostasis is obvious from the pathology of the hemophilias; its importance in venous thrombosis goes undisputed. Apart from platelet adhesion and aggregation, also thrombin generation must play a key role in arterial thrombosis because heparin administration as well as oral anticoagulation prevent coronary reinfarction $(8,9)$. Many clinical and experimental observations support this conclusion (10-14). The interactions between the platelet and the clotting system are many and varied. Thrombin is a very potent platelet activator and the generation of thrombin in PRP is strongly dependent upon platelet function. Blocking GPIIb/IIIa with an antibody e.g. inhibits thrombin generation (15), fibrin activates the procoagulant activity of platelets and von Willebrand factor is required for normal thrombin generation in PRP (16). Thrombin generation is diminished by pharmaceutical interference with platelet function by aspirin (17), with GPIIb/IIIa antagonists $(18,19)$ and with clopidogrel $(20)$. In a group of 41 young stroke patients we found increased thrombin generation in the PRP of over half of the patients, only in one quarter of all patients this could be attributed to hypercoagulability of the PPP (21). This indicates that there exists a platelet-dependent form of hypercoagulability that can be found via the thrombogram of PRP.

Interactions between the platelet and the clotting system easily escape our attention because clotting is studied in platelet poor plasma and platelets are studied in anticoagulated plasma or in buffer.

Thrombin generation as a probe of the clotting function of blood stems from the $19^{\text {th }}$ century (e.g. 22) and was a principle means of investigation until the 1960s. Technically it was executed by timed subsampling from clotting blood or plasma on a fibrinogen solution $(2,3)$, a method that is so labor intensive as to restrict its use to specialized laboratories. The subsampling technique cannot be used on the large scale required for modern clinical, epidemiological and pharmaceutical research. An alternative, the whole blood or PRP clotting time 
represents the lag-time of thrombin appearance (5) and thus yields only a small fraction of the information contained in the complete thrombin generation curve. Other features, such as peak height, time-to-peak and area under the curve (ETP) may vary independently of the lag time and indicate abnormal function even if the lag-time, and therefore the clotting time, is normal (see e.g. Figs. 2, 3).

Previously we developed a method to monitor the thrombogram in defibrinated plasma via the OD-changes resulting from the splitting of a suitable chromogenic thrombin-substrate (1). We showed that thrombin generation in PPP is decreased by any type of anticoagulation tested and increased in plasma based hypercoagulant states (23). Because of the defibrination, required to maintain transparency of the sample, this method cannot be applied to PRP. Fig.1 shows that the fluorescent signal is not hampered by fibrin formation and platelet related turbidity changes.

The present results have been obtained with a routine fluorometer and require averaging of the signal, off-line, in a spreadsheet. On line signal averaging and calculation of the first derivative in a dedicated instrument would allow to obtain the thrombogram directly. The correction for the thrombin like activity that is due to $\alpha 2$-macroglobulinbound thrombin, appears to be much smaller in fibrinogen containing media than that in defibrinated plasma, so that the first derivative of the fluorescence curve already gives a first impression of thrombin generation during the course of the experiment.

We conclude that the fluorimetric approach allows to probe thrombin generation in PRP easily and thereby opens the possibility to routinely assess the function of a large subsystem of the haemostaticthrombotic mechanism. From the results previously obtained via the subsampling method, one infers a wide applicability of this test as a diagnostic tool, as a monitor of antithrombotic drugs and as an indicator of pharmaceutical activity.

\section{References}

1. Hemker HC, Wielders S, Kessels H, Béguin S. Continuous registration of thrombin generation in plasma, its use for the determination of the thrombin potential. Thromb Haemost 1993; 70: 617-24.

2. Biggs R, Macfarlane RG. Human Blood Coagulation and its Disorders. Blackwell Scientific Publications, Oxford 1953.

3. Seegers W. Prothrombin. Harvard University Press, Cambridge Mass. 1962.

4. Béguin S, Kumar R. Thrombin, fibrin and platelets: a resonance loop in which von Willebrand factor is a necessary link. Thromb Haemost 1997; 78: 590-4.

5. Béguin S, Lindhout T, Hemker HC. The effect of trace amounts of tissue factor on thrombin generation in platelet rich plasma, its inhibition by heparin. Thromb Haemost 1989; 61: 25-9.

6. Hemker HC, Willems GM, Béguin S. A computer assisted method to obtain the prothrombin activation velocity in whole plasma independent of thrombin decay processes. Thromb Haemost 1986; 56: 9-17.
7. Hemker HC, Béguin S. Thrombin generation in plasma: its assessment via the endogenous thrombin potential. Thromb Haemost 1995; 74: 134-8.

8. Neri Serneri GG, Rovelli F, Gensini GF, Pirelli S, Carnovali M, Fortini A. Effectiveness of low-dose heparin in prevention of myocardial reinfarction. Lancet 1987; 1: 937-42.

9. A double-blind trial to assess long-term oral anticoagulant therapy in elderly patients after myocardial infarction. Report of the Sixty Plus Reinfarction Study Research Group. Lancet 1980; 2: 989-94.

10. Agnelli G. Thrombin plays a pivotal role in vascular re-occlusion after PTCA and coronary thrombolysis. Cardiovasc Res 1996; 31: 232-4.

11. Badimon L., Meyer BJ, Badimon JJ. Thrombin in arterial thrombosis. Haemostasis 1994; 24: 69-80.

12. Chesebro JH, Zoldhelyi P, Badimon L, Fuster V. Role of thrombin in arterial thrombosis: implications for therapy. Thromb Haemost 1991; 66: $1-5$.

13. Heras M, Chesebro JH, Penny WJ, Bailey KR, Badimon L, Fuster V. Effects of thrombin inhibition on the development of acute plateletthrombus deposition during angioplasty in pigs. Heparin versus recombinant hirudin, a specific thrombin inhibitor. Circulation 1989; 79: 657-65.

14. Jang IK, Gold HK, Ziskind AA, Leinbach RC, Fallon JT, Collen D. Prevention of platelet-rich arterial thrombosis by selective thrombin inhibition. Circulation 1990; 81: 219-25.

15. Reverter JC, Béguin S, Kessels H, Kumar R, Hemker HC, Coller BS. Inhibition of platelet-mediated, tissue factor-induced thrombin generation by the mouse/human chimeric 7E3 antibody. Potential implications for the effect of c7E3 Fab treatment on acute thrombosis and "clinical restenosis". J Clin Invest 1996; 98: 863-74.

16. Béguin S, Kumar R, Keularts I, Seligsohn U, Coller BS, Hemker HC. Fibrin-dependent platelet procoagulant activity requires GPIb receptors and von Willebrand factor. Blood 1999; 93: 564-70

17. Szczeklik A, Musial J, Dropinski J, Krzanowski M, Krolikowski W, Undas A, Swadzba J, Duplaga M, Bodzon W. Thrombinogenesis and its pharmacological modulation in atherosclerosis. J Physiol Pharmacol 1994; 45: 3-11.

18. Keularts IM, Béguin S, de Zwaan C, Hemker HC. Treatment with a GPIIb/ IIIa antagonist inhibits thrombin generation in PRP from patients. Thromb Haemost 1998; 80: 370-1.

19. Hérault JP, Peyrou V, Savi P, Bernat A, Herbert J-M. Effect of SR121566A, a potent GP IIb-IIIa antagonist on platelet-mediated thrombin generation in vitro and in vivo. Thromb Haemost 1998; 79: 383-8.

20. Hérault J-P, Dol F, Gaich C, Bernat A., Herbert J-M. Effect of Clopidogrel on thrombin generation in platelet-rich plasma in the rat. Thromb Haemost 1999; 81: 957-60.

21. Faber K. Thrombotic tendency in young stroke patients. The thrombin potential as a screening parameter for coagulation disturbances. Thesis Universiteit Maastricht, 1998. ISBN 90-9012009-2.

22. Pekelharing $C$ A. Untersuchungen über das Fibrinferment. Verhandelingen der Koninklijke akademie van Wetenschappen (Reports of the Royal Academy of Sciences) Amsterdam. Tweede sectie 1893; 1: 3 - 52.

23. Wielders S, Mukherjee M, Michiels J, Rijkers DT, Cambus JP, Knebel RW, Kakkar V, Hemker, H.C, Béguin, S. The routine determination of the endogenous thrombin potential, first results in different forms of hyper- and hypocoagulability. Thromb Haemost 1997; 77: 629-36.

Received July 20, 1999 Accepted after revision November 23, 1999 